\title{
sciendo
}

\author{
Current Issues in Pharmacy and Medical Sciences \\ Formerly ANNALES UNIVERSITATIS MARIAE CURIE-SKLODOWSKA, SECTIO DDD, PHARMACIA
}

journal homepage: http://www.curipms.umlub.pl/

\section{A variety of processes that affect the perception of skin aging}

\author{
Dorota KASPrZaK ${ }^{1 *}$, Artur WNOROWSKI ${ }^{2}$ \\ ${ }^{1}$ Chair and Department of Embryology with Experimental Cytology Unit, Medical University of Lublin, Radziwillowska 11, 20-080 Lublin, \\ Poland \\ ${ }^{2}$ Department of Biopharmacy, Medical University of Lublin, Chodzki 4a, 20-093 Lublin, Poland
}

\begin{tabular}{|c|c|}
\hline ARTICLE INFO & ABSTRACT \\
\hline $\begin{array}{l}\text { Received } 25 \text { January } 2019 \\
\text { Accepted } 11 \text { April } 2019\end{array}$ & $\begin{array}{l}\text { The purpose of this paper is to discuss the most important factors affecting perceived } \\
\text { age. Aging is an unavoidable and irreversible process, but perceived age is a modifiable }\end{array}$ \\
\hline $\begin{array}{l}\text { Keywords: } \\
\text { skin aging, } \\
\text { wrinkles, } \\
\text { age perception, } \\
\text { grey hair, } \\
\text { skin color, } \\
\text { glycation. }\end{array}$ & $\begin{array}{l}\text { psychosocial factor. Our exterior has become one of the determinants of our social } \\
\text { position, the key to success in our professional and personal lives. Today, we see people } \\
\text { through their appearance, we judge after the first impression. With the help of aesthetic } \\
\text { medicine, we can change the perceived age, but we cannot stop aging. This article discusses } \\
\text { factors affecting the perceived age, such as hair color, skin color, general appearance and } \\
\text { environmental factors. Many cannot be avoided, but we can make changes in life to look } \\
\text { younger and more well-groomed. Indeed, we can change our habits for the benefit of the } \\
\text { whole body, not only for the skin. }\end{array}$ \\
\hline
\end{tabular}

\section{INTRODUCTION}

Evaluating others based on appearance is a common practice in society, although it is often denied. This is due to the action of our brain, which makes it easier to build a picture of another person by appearance than by analyzing all the nuances that crop up during interaction with another person [1]. Our mind holds a limited information processing capacity and is unable to analyze the majority of details that arise during a brief encounter with another person. Due to the extent of information that is automatically transmitted to us, an individual ceases to be internally motivated to explore other people. This situation leads to the stereotypical thinking that is simplified and grounded in our consciousness.

Our appearance speaks to us very much. Indeed, scientists have shown that perceived age is also related to the real age of the body. Available data indicate that genes responsible for aging of the body are related to perceived age [2] and up to 1500 different genes may be involved in skin aging [3]. Physicians know this and often take into account the perceived age in assessing the patient's health condition. Perceived age is related to the risk of mortality in older people [4] with regard to the physical condition of the person, with life span and even the length of the leucocyte telomeres [2]. For example, recent studies show a link between male pattern baldness and earlobe crease and heart disease [5], the perceived age of women and the risk of osteoporosis [6].

\footnotetext{
* Corresponding author

e-mail: dorota.kasprzak@outlook.com
}

We see those who smoked cigarettes, drink excessively, and exposed themselves to UV (ultraviolet) radiation as being older [7], but what depends on the perception of age?

Skin aging is a natural process that involves reducing the biological activity of body cells, slowing down the regenerative processes and losing adaptive capacity as the organism ages. There are two types of skin aging: endogenous (inherited) and exogenous - due to outside factors [8]. The first type of aging is related to age, genetic, hormonal and internal factors. The latter depends on environmental factors.

The process of aging involves genetic factors such as programmed, controlled cell death [9], internal factors associated with hormonal regulation disorders, abnormal nutrition and external factors that are involved in aging to the extent of $33 \%$. External factors include UV radiation (photo-aging), environmental pollution, smoking, second hand cigarette smoke, air conditioning, improper care, ionizing radiation (e.g. Computers), excess ozone, air pollution - bacteria, car exhaust, lack of physical activity, short time in the open air and improper nutrition.

Each cell has a life-cycle-coded and end-of-life program. There are about 100 genes involved in this process. These are the genes responsible for stress response, cell cycle progression and energy metabolism. It is also well established that intracellular oxidative damage to DNA results in an accelerated aging.

There are several theories about how aging occurs. The mitochondrial theory holds that the number and 
activity of mitochondria decreases with age, which in turn, impairs the cell regenerative capacity [10]. The membrane theory puts forward that aging is driven by changes in cell membrane composition and lipid growth, which hinders transport through cell membranes and consequently leads to the accumulation of toxic substances within the cytoplasm [11]. The theory of a limited number of cell divisions assumes that cells divide a certain number of times and then die. Finally, the theory of protein disorders indicates that the ability of protein synthesis decreases with advance age, which results in impaired normal cell functioning [12].

\section{FACIAL FEATURES AFFECTING AGE PERCEPTION}

\section{Skin color}

According to current research [13-16] and universal opinion, skin color definitely affects perceived age. Fink et al., in a study of 170 British women, randomly showed their pictures to participants. Women with uneven skin color appear less attractive and older. In addition, their study showed that males preferred less-melanized or brightly colored females [13]. Skin color can add 10-12 years to the perceived age. Skin color is the result of melanin, hemoglobin distribution and blood vessels. With age, the capillaries undergo change, resulting in high capillary fragility and the tendency to erythema and rupture. Chronic exposure to ultraviolet (UV) irradiation or the effects of endogenous or exogenous phototoxic substances or stimulating melanogenesis, such as estrogens, may result in uneven distribution of pigment resulting in discoloration [17]. Skin becomes freckled and lenities start to appear. This comes about because melanin is secreted in a non-uniform way. Herein, freckles are a disorder of the pigment distribution in the skin that results from the rapid synthesis of melanin by melanocytes [18]. The changes are genetic in nature, the inheritance is autosomal and dominant [19]. Beyond the aforementioned, post-inflammatory hyper pigmentation (PIH) changes the color of the skin. Among the most common causes of PIH are acne, skin trauma and medical treatments (e.g. peels or laser treatments). PIH is more common in people with darker complexion, but these discolorations often disappear spontaneously [20]. Speaking of discoloration, one should mention about breloque dermatitis. This is a discoloration that can occur after applying perfume enriched with bergamot oil. The changes take the form of brown spots that appear at the site of the perfume application [21]. The name of the discoloration is related to the fact that it often takes the form of a pendant (fr. breloque). Discoloration in the form of darkening of facial skin also increases in women before menstruation [22]. Jones et al. photographed women five times at intervals of one week and found that facial skin was redder when estradiol levels were relatively high [23]. They note that estradiol levels heighten during the late follicular phase but can also remain high during the early luteal phase [24]. The spontaneous appearance of hormonal discoloration can come about due to pregnancy, use of oral contraceptives or through hormone replacement therapy (HRT) and other hormonal treatments, via the menopause period, liver disease, adrenal insufficiency, hyperthyroidism and through phytotoxic or photo allergenic substances found in medicines, cosmetics and soaps. It makes its appearance under the influence of solar radiation.

\section{Wrinkles}

The first wrinkles appear between 25 and 30 years of age. They bend and deform the skin, and are inevitable. Their formation is determined by many environmental, genetic and individual factors. Skin wrinkling is strongly related to looking older [25]. It is especially notable in the lip areawhere we see volume changes and upper lip wrinkles; the eye area - via features known as crow's feet, under-eye wrinkles, dark circles and bags under the eyes; and in skin tone uniformity - brown spots, skin color uniformity [26]. Due to these natural happenstances, people over the age of 60 are seen as less attractive than are younger [27].

Wrinkles are grouped in the following manner: The dynamic group - they are formed perpendicular to the shrinking muscle, in places of intense facial expressions, i.e. around the eyes, mouth, chin and forehead; Fibroblasts, due to shrinkage and mal-function of mimic muscles - this is the so-called 'skin softening'. Static group - these are wrinkles that get worse over time and are visible on the face, no matter the facial expression - these come about due to the natural aging of collagen fibers, as well as genetic and lifestyle factors [28]; Static wrinkles - these may result from overexposure to sunlight, smog or nicotine smoke. Wrinkling can also come about because of inappropriate care products, poor hygiene and the use of low-quality color cosmetics. Another cause may be lack of vitamin A, C and E in the diet, smoking or the overuse of stimulants or depressives such as coffee and alcohol (Fig. 1).

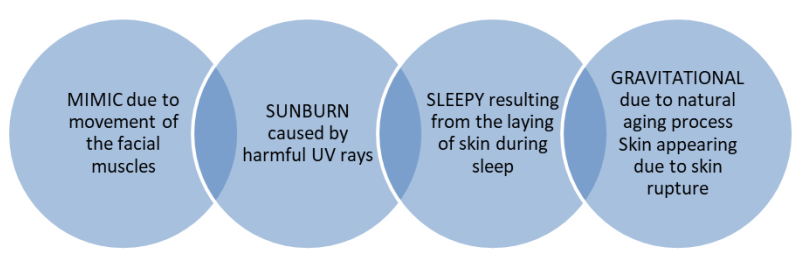

Figure 1. Wrinkles are divided into 4 groups due to their cause

\section{Emotional expression}

Emotional expression is a significant determinant of perceived age [29]. Positive facial expression could be expected to trigger positive stereotypes when assessing age, and negative facial expressions might have the opposite effect [30]. Smiling makes people appear friendlier and more attractive than does the display of a neutral expression [31]. Stereotypically, it is believed that smiling people look younger. For example, young people judge smiling people as being younger and sad people as being older [32]. However, a single study has shown that excessive smiling can generate an overestimation of perceived age. This is because a smile leads to the narrowing of the eyes, which makes us perceive the face as being that of an older individual $[33,34]$. Interestingly, facial expressions affect not only the perceived age, but also the perception of weight loss - especially in men. Herein, a sad face generates the perception of a meatier face and build [35]. 


\section{The size of the lips and the nasolabial fold}

Changes in shape and size of the mouth with age are associated with the disappearance of collagen and elastin, as well as with changes in teeth and tissues in the jaw. Lip size is established during development and then decreases in size during the adult life-span [36]. However, lip size is associated with female attractiveness [37]. With age, the lips become narrow and small, therefore, full firm lips are identified with a youthful appearance. Full lips indicate youth and are, hence, considered attractive. The natural shape of the lips and equal proportionality are also important. When the upper lip is unnaturally enlarged to the lower lip, the overall image of the face looks unfavorable, the face looks unnatural, plastic [38]. With age, the corners of the mouth fall down gravitationally. Here, nasolabial fold appearance has been linked to changes in the redistribution of facial fat due to aging [39]. Moreover, the products of combustion and air pollution deepen the nasolabial fold [40]. What is more, with age, the human nose widens and the tip of the nose falls as a result of the dorsal muscles of the nose loosening (Table 1).

Table 1. Specified sequence of appearance of wrinkles

\begin{tabular}{|c|c|}
\hline Age & Signs of aging \\
\hline 30 years & $\begin{array}{l}\text { the excess of skin on the upper lids causes them } \\
\text { to fall, the so called "Crow's feet" in the lateral outer } \\
\text { corners of the eye }\end{array}$ \\
\hline 40 years & $\begin{array}{c}\text { prominent nasal - lumbar folds, transverse wrinkles } \\
\text { of the forehead and intermittent vertical wrinkles } \\
\text { (wrinkles lion) }\end{array}$ \\
\hline 50 years & $\begin{array}{c}\text { sagging of the nose, less prominent jaw line, neck } \\
\text { wrinkles falling sideways of the cheeks and formation } \\
\text { of the so called "hamsters" }\end{array}$ \\
\hline 60 years & $\begin{array}{c}\text { skin thinning and subcutaneous tissue loss contributing } \\
\text { to wrinkles and skin }\end{array}$ \\
\hline 70 years, 80 years & $\begin{array}{c}\text { flabbiness, upper lip wrinkles, gums, cheeks, } \\
\text { fat reduction }\end{array}$ \\
\hline
\end{tabular}

\section{Hair color}

This is not a very pleasant process, but unfortunately it is something natural. Hair colour depends on melanin content in the hair bulb. With age, melanocytes produce less melanin and hair loses its natural color [41]. Research has shown that people using hair dye products look a lot younger [42], but there is no accurate repeatable scientific data on how exactly gray hair affects the perceived age, yet we know that the difference is significant [43] In addition, colouring damages the hair follicles. Blond hair is seen as more attractive only by the male population. However, blonde hair does not mean that the person is perceived as healthier than is someone dark haired [44]. People with dark hair are often seen being youthful, especially if they also have a darker shade of skin. Yet other factors come into play with regard to greying. These include genetics, nutrition and metabolic disorders. Such factors change the hair structure and alter its optical properties [45]. Studies have also shown a link between smoking and faster greying, because smoking damages the hair follicles [46]. Moreover, it is said that sugar, which inhibits the effects of vitamin E, which is significantly involved in healthy hair growth, can have a significant effect. In addition, it is suspected that sugar inhibits the absorption of proteins, vitamins and minerals that provide healthy, strong hair. Too much animal protein is transformed into uric acid. Some people suspect that this promotes the formation of gray hair.

\section{Hair loss}

Some doctors classify baldness as a psychodermatological disease because, in society, men with dense and thick hair are considered more sexy and energetic. Moreover, such gentlemen are perceived as caring for their appearance and health, and biologically considered more fertile. Around $80 \%$ of the variation in male pattern baldness in youth and maturity can be attributed to genetic factors [47]. The results confirm the expected associations between looking older and having more grey hair and, in men, having extensive hair loss. In women, hair thinning is also perceived symptom of aging [43]. However, in women, the problem of baldness is much more serious, and is perceived as due to health issues.

\section{Androgenetic alopecia}

This baldness affects up to $50 \%$ of all men by the age of 50 years, and up to $70 \%$ of all men in later life [48]. It also affects $6 \%$ of women aged under 50 years and $30-40 \%$ of women aged 70 years and over [49]. The cause is the same - natural histopathological properties of hair follicles, specifically, progressive reduction in diameter, length and pigmentation of the hair. Early treatment at the onset of its first symptoms may delay its development for many years and reduce the degree of alopecia [50].

\section{Alopecia areata, diffuse and generalized}

Alopecia areata occurs mostly on the scalp in the form of one or more round or oval hairless foci without signs of inflammation. These lesions can spread in the form of diffuse hair loss over the entire surface of the head or in the form of generalized deprivation of hair. This can also occur within the eyebrows, lashes, armpits and genitalia, as well as the beard. The course of Alopecia areata spread is different in different individuals. It can persist for a variable time period and be sometimes recurrent and not necessarily become generalized. It can occur in both adults and children. Alopecia areata is thought to be due to an autoimmune process, thus, genetic background and stressors are taken into account in treatment [51].

\section{Telogen baldness}

This form of baldness, Telogen effluvium (TE), involves the simultaneous entering of an increased amount of hair into the telogen phase, i.e. the natural end of the growth phase of the hair prior to hair loss. It is caused by irritating external or internal factors. Telogen baldness is one of the most common cause of alopecia [52]. Women have a greater tendency to experience this condition because hormonal changes in the postpartum period are a frequent cause of TE. The specific form of such effect is telogen gravidarum TG, where anagen prolongation occurs under the influence of pregnancy hormones. It is estimated that TG affects onethird to half of women after childbirth [52]. A similar state occurs after discontinuation of contraceptive pill [53]. TE baldness also occurs in 7\% of all HIV-1 infected individuals [54]. 


\section{Anagenic baldness}

Herein, the hair is sparse and does not grow long. This is a recently described disease called 'short anagen syndrome' (SAS). It is characterized by a short anagene phase [55]. However, knowledge in this area is incomplete. This syndrome is not associated with systemic diseases. The main differential diagnosis is LAS (loose anagen syndrome), wherein the hair does not grow long because of a defective adhesion of the hair shafts to the follicle [56].

\section{Alopecia in menopausal period}

Alopecia in females can be related to the change of the hormonal economy during the menopausal period. Hair loss occurs at the top of the head and may include pubic and armpit pains. The combination of hair diameter and density into a single metric of hair 'amount' suggests a dramatic impact on the perception of hair loss that occurs in the mid-late forties [57]. While there is not much data, it is recognized that in women, alopecia alters their perceived age, social perception and self-esteem. For some women, hair loss can be such a mental problem that they will refuse chemo or radiation therapy [58].

\section{ENVIRONMENTAL AND LIFE STYLE FACTORS AFFECTING PERCEIVED AGE}

\section{Smoking}

It has long been recognized that smokers look older [59]. Hence, smoking is significantly associated with increased perceived age. Indeed, smoking 20 cigarettes a day for 20 years has the same effect on perceived age as aging 1 full year [60]. Because of smoking, the individual grays and wrinkles earlier [46]. Smokers' skin has been characterized by prominent facial wrinkling particularly around the mouth and upper lip and eyes [62]. Yet, women are less susceptible to aging from cigarettes and statistically appear younger than men. This may be due to the fact that statistically fewer women are smokers. This aging effect comes about because tobacco smoking leads to higher expression of MMP-1 and MMP-3 that break down collagen type I and III [61].

\section{Outdoor work}

Outdoor work is associated with being exposed to constant UV radiation, and excessive exposure to the sun has been shown to be associated with premature skin wrinkling or facial ageing [63], hence increasing the perception of age. This has a caveat in that age perception is noted in men rather than women [60]. Moreover, outdoor work means greater exposure to air pollution, which also induces premature aging of the skin. It should be noted that UV radiation dramatically increases the formation of reactive oxygen species (ROS) and accelerates actual aging [64].

\section{Obesity}

It is commonly believed that obese people look younger because they have less visible wrinkles. Body mass index (BMI) has been proven to be inversely related to degree of wrinkling [65]. At age 70, the obese do look younger than peers of normal weight. The connection between obesity and perceived age, however, requires further research.

\section{Education level}

The level of education and the related level of social standing affect perceived age. Increased household income is associated with improved attention to cleanliness, hygiene and care. Persons with better education may be able to afford medical visits and enjoy better health service. In social research, women who have not been to the doctor within the previous 12 months have been assessed as being much older than those who go did [66]. People with less education often have to work more. Physical work and overwork is often combined with stress and has a negative impact on aging and appearance. People with lower education do not always have the time to rest, which is reflected in the condition of their skin [67]. The difference in wrinkles associated with education is particularly significant in women.

\section{Nutrition}

The affect on appearance of eating habits and choice is a topic that is still not fully understood, yet is controversial. Studies, however, have shown that a diet rich in anti-oxidants may delay the effects of aging. It is therefore recommended to have a diet rich in vitamins and related antioxidants. Moreover, refined sugars can have harmful effects on the skin through the process of glycation [68]. Grilling, frying, deep fat frying, and roasting methods are all known to produce higher levels of Advanced glycation end-products (AGEs) in food [69]. In contrast, some dietary compounds such as cinnamon, cloves, oregano, allspice, ginger, garlic, $\alpha$-lipoic acid, carnitine, taurine, carnosine, flavonoids, benfotiamine, $\alpha$-tocopherol, niacinamide, pyridoxal, sodium selenite, selenium, yeast, riboflavin, zinc and manganese are believed to inhibit the endogenous production of AGEs [70-72].

\section{Alcohol consumption}

Research has shown that drinking alcohol increases the risk of sunburn associated with UV radiation. This comes about because consumption of alcohol brings about a decrease in the concentration of antioxidants and this impairs the mechanisms of self-defense of the skin against the sun [73]. What is more, alcohol consumption has a synergisic effect on exposure to UV radiation, and is associated with the risk of skin cancer and melanoma [74]. In a study involving twins, a younger perceived age was observed in the twin who avoided excessive alcohol consumption [75].

\section{Use of personal skin care products for the face}

The use of facial care cosmetics is widespread and increasing steadily [76]. Cosmetics significantly influence perceived age as effective use of cosmetics hides the effects of aging. Moreover, on average, people who never use face washing soaps look about 4.27 years older than those who often use this item [66]. Anti-aging cosmetics are becoming more effective through the application of science and by means of public awareness. Cosmetics of quality are well worth using, especially medically approved cosmetics for treating specific skin problems [77]. 


\section{Pollution}

In today's world, more attention is paid to the air pollution that damages the skin. Although the skin has protective functions against toxic compounds in the air, this comes at a cost. Herein, the damage that is incurred intensifies the damage brought about by UV radiation. The majority of outdoor pollutants come from anthropogenic sources, such as vehicle emissions, fossil fuel combustion and the gasses released through industrial processes [78]. $\mathrm{NO}_{2}$, which is generated by automobile exhaust, is responsible for visible cheek lentigines. $\mathrm{NO}_{2}$ can undergo photolysis, with generation of reactive breakdown products that can potentially affect both the skin and lungs [79]. However, the risks associated with air quality go beyond just this compound. Phthalates that can be found in dust particles as contaminants, originating, for instance, from home furniture, can disrupt the differentiation and proliferation of keratinocytes, impairing skin barrier function [80]. Ambient air pollutants generate free radicals that also engender cutaneous inflammatory cascades by activating aryl hydrocarbon receptor (AhR)-dependent mechanisms and altering cutaneous microflora [81]. AhR is a ligand-activated transcription receptor founding in various skin cells, including keratinocytes, fibroblasts and melanocytes [82]. Activation of AhR may affect the biological function of cells. AhR performs its function in a context-dependent manner and is very specific to the cell type [83]. The concentration of toxic substances in the air in larger agglomerations often exceeds the permitted standards by more than half. WHO estimates that in 2012 around 1 in 8 deaths were attributed to exposure to air pollution. Today, we do not have effective weapons to defend ourselves against air pollution. If we do not change our approach to the state of air, we will bear the consequences in the future.

\section{Stress}

The effect of psychological stress on the autonomic nervous system, renin-angiotensin system (RAS), and hypothalamus-pituitary-adrenal (HPA) system is well established [84]. Long-term stress leads to oxidative stress, while chronic stress brings about ROS dysfunction and DNA damage [85]. Oxidative stress specifically has an ill-effect on the promoters for the genes responsible for cellular maintenance, including antioxidant and DNA repair enzymes [86]. In the skin, free radicals can destroy cells and cellular components, including that making up collagen and elastin fibers [87].

\section{MOLECULAR MECHANISMS MODULATING PERCEIVED AGE}

\section{Glycation}

Glycation is the phenomenon of the covalent bonding of a sugar molecule to a protein, which consequently may impair its function. As a result of the glycation reaction, molecules called 'AGE' (advanced glycation end products) are formed. The higher the blood sugar, the faster the reaction takes place. After eating a meal rich in sugar, the blood glucose level rises rapidly. Insulin cannot cope with its processing, thus, the glucose molecules attach to the proteins in the cells [88]. AGE molecules destroy collagen and elastin. These are the skin's supporting fibers and are responsible for youthful appearance. Naturally, collagen type III is common in youth, and with time is supplanted with type I collagen, which predominates in the skin of the elderly. However, sugar affects the type of collagen that predominates in the skin, converting type III collagen to type I collagen. Type I collagen is stiffer and more brittle which makes the skin seemingly age [89]. What is more, AGE molecules deactivate natural antioxidants in the skin. This makes it more sensitive to sunlight, which also accelerates aging. In addition, sugar affects the formation of pustules and imperfections [90]. Glucose not only contributes to the formation of wrinkles, but also to the formation of cellulite, because it modifies fat to be non-metabolical, hence, it is deposited under the skin in the form of fatty lobules. Of interest, current research shows that the skin autofluorescences with chronological aging and this outcome correlates with skin deposition of AGEs, making this method a potential tool in investigating the effect of various anti-aging [91,92]. Our recommendations on limiting the harmfulness of the glycation process have been shown in (Fig. 2).

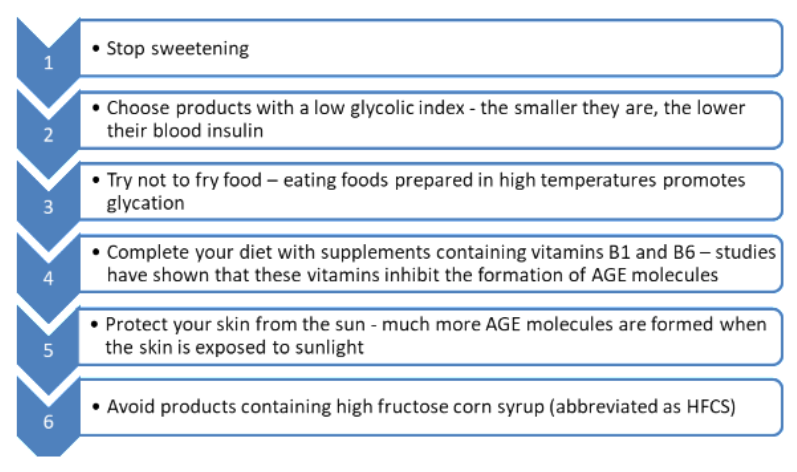

Figure 2. Our recommendations to stop glycation

\section{ROS}

The simplest definition of ROS is that it is a highly reactive chemical entity that has in its structure, an atom with an unpaired electron which makes it immensely capable of generating chain reactions which form free radicals at each step [93,94]. ROS is the main reason for oxidative stress leading to oxidative damage in biological structures [95]. ROS causes DNA damage, oxidation of proteins and specific enzymes, as well as lipid peroxidation. The aforementioned result in damage to cells and their extracellular environment. Skin aging is associated with oxidative metabolism and subsequent ROS generation [96]. UV radiation, exposure to certain hormones, stress, environment pollution and improper diet increase ROS production and oxidative stress. Consequently, this results in faster aging and the appearance of deeper wrinkles. There is no possible way to defend against oxidative stress beyond maintaining healthy habits, limiting skin exposure to UV radiation, and ensuring adequate diet. 


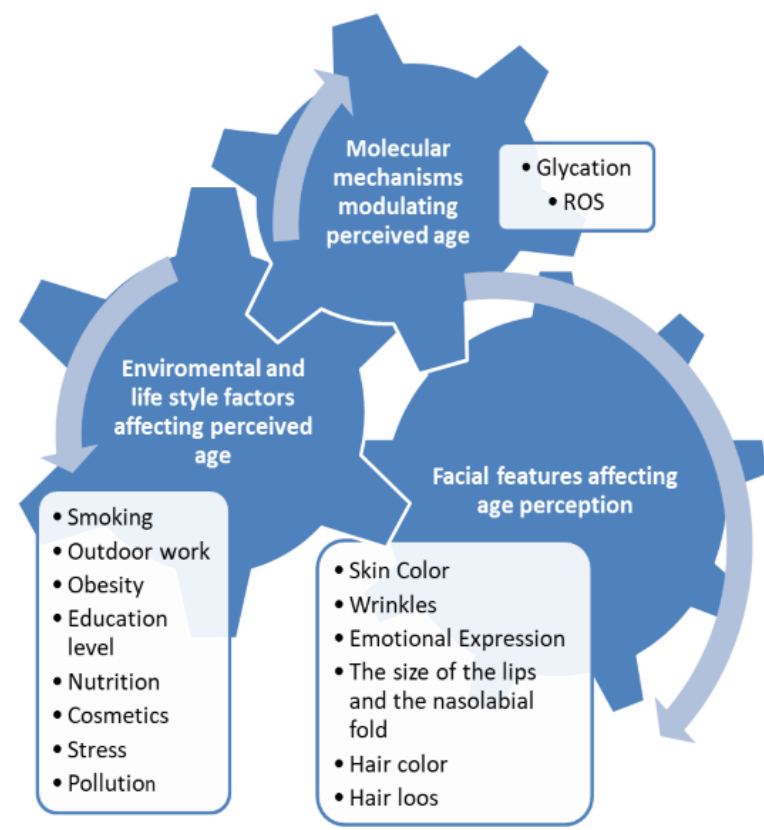

Figure 3. Factors affecting perceived age

\section{CONCLUSIONS}

The aim of this work was to collect and discuss the various processes that influence the perception of skin aging. First impressions based on facial appearance occur automatically, are difficult to overcome and impact decision-making [97]. For many people, the perceived appearance is very important. Today, we try to look good. Nevertheless, many people still neglect their facial appearance. With today's development of science and aesthetic medicine, generating or maintaining a younger appearance is much simpler [98]. The possibilities to eliminate wrinkles, smooth the skin, contour the face, dye the hair and maintain a healthy lifestyle are in reach for more people. The impact of the same environmental factors on the perceived age is greater in the younger generations. It is not prudent to damage the environment in which we live, and which affects our whole health, not just our external appearance. There are many things that we should change. The pollution of air, water and food sources is a problem and a challenge for future generations. Although many people neglect, and for some reason, do not care about their appearance in general, people look younger than they once look at their real age, if we compare now with olden times [99]. Applying face creams has become a routine. Contemporary cosmetics are becoming more effective and our knowledge is expanding so we can maximize the slowdown of the aging process and our perceived age. Cosmetics and facial care have a significant impact on our appearance [100], and the condition of our hair and teeth are some of the few attributes that are significant on first impression. From a scientific point of view, the recognition of the role of molecular processes such as glycation in the skin aging process and in general health and well-being is a positive development. The scientific basis of aging has become more understood even by the lay-man. Following a healthy lifestyle, natural nutrition, taking care of oneself is trendy and fashionable. Knowledge in the topic of anti-aging is developing fast and has made great progress over the years. We have been able to learn about the internal and external factors that affect our outer appearance, we can keep our youth for longer, and the topic of aging and appearance is becoming more and more exploited by scientists, as evidenced by the growing number of publications on this subject. Our conclusions have been compiled in (Fig. 3). We hope that the dissemination of knowledge about the harmful effects of solar radiation and the misuse of stimulants such as alcohol and drugs will affect the conscious limitation of these factors in society.

\section{CONFLICT OF INTEREST}

The authors declare that there is no conflict of interest regarding the publication of this article.

\section{REFERENCES}

1. Willis J, Todorov A. First impressions: Making up your mind after a 100-ms exposure to a face. Psychol Sci. 2006;17(7):592-8.

2. Christensen K, Thinggaard M, McGue M, Rexbye H, Hjelmborg JVB, Aviv A, et al. Perceived age as clinically useful biomarker of ageing: Cohort study. BMJ. 2009;339(7735):1433.

3. Weinkle SH, Tiesman JP. Genomics of skin aging: practical applications. J Drugs Dermatol. 2009;8:3.

4. Uotinen V, Rantanen T, Suutama T. Perceived age as a predictor of old age mortality: A 13-year prospective study. Age Ageing. 2005;34(4):368-72.

5. Christoffersen $\mathrm{M}$, Tybjærg-Hansen A. Visible aging signs as risk markers for ischemic heart disease: Epidemiology, pathogenesis and clinical implications. Ageing Research Reviews. 2016;25:24-41.

6. Nielsen BR, Linneberg A, Christensen K, Schwarz P. Perceived age is associated with bone status in women aged 25-93 years. Age (Omaha). 2015;37(6):106.

7. Sherertz EF, Hess SP. Stated age. N Engl J Med. 1993;329(4):281-2.

8. Nguyen HP, Katta R. Sugar Sag: Glycation and the Role of Diet in Aging Skin. Skin Therapy Lett. 2015;20(6):1-5.

9. Puizina-Ivić N. Skin aging. Acta dermatovenerologica Alpina, Pannonica. Adriat. 2008;17(2):47-54.

10. Chistiakov DA, Sobenin IA, Revin V V, Orekhov AN, Bobryshev Y V. Mitochondrial aging and age-related dysfunction of mitochondria. BioMed Res Int. 2014;2014:238463.

11. Zs-nagy I. I. Aging of cell membranes: Facts and theories. Aging: Facts and Theories. 2014;39:62-85.

12. Macieira-Coelho A. Control of Cell Replication during Aging. Interdiscip Top Gerontol. 2014;39:24-44.

13. Fink B, Grammer K, Matts PJ. Visible skin color distribution plays a role in the perception of age, attractiveness, and health in female faces. Evol Hum Behav. 2006;27(6):433-42.

14. Fink B, Butovskaya M, Sorokowski P, Sorokowska A, Matts PJ. Visual perception of British Women's skin color distribution in two nonindustrialized societies, the Maasai and the Tsimane. Evol Psychol. 2017;15(3):1-4.

15. Porcheron A, Mauger E, Soppelsa F, Liu Y, Ge L, Pascalis O, et al. Facial contrast is a cross-cultural cue for perceiving age. Front Physiol. 2017;8:1208.

16. Wang JJ, Jakobsen K, Smith W, Mitchell P. Five-year incidence of agerelated maculopathy in relation to iris, skin or hair colour, and skin sun sensitivity: The Blue Mountains Eye Study. Clin Exp Ophthalmol. 2003;31(4):317-21.

17. Dalli D, Ogce F, Okcin FA. Knowledge of the effects of sun exposure of Turkish high school students and their sun bathing habits. Asian Pacific J cancer Prev APJCP. 2004;5(4):366-9.

18. Praetorius C, Sturm RA, Steingrimsson E. Sun-induced freckling: Ephelides and solar lentigines. Pigment Cell Melanoma Res. 2014; 27(3):339-50.

19. Bataille V, Snieder H, MacGregor AJ, Sasieni P, Spector TD. Genetics of risk factors for melanoma: An adult twin study of nevi and freckles. J Natl Cancer Inst. 2000;92(6):457-63. 
20. Ebanks JP, Wickett RR, Boissy RE. Mechanisms regulating skin pigmentation: The rise and fall of complexion coloration. Int Journal of Mol Sci. 2009;10:4066-87.

21. Gruson LM, Chang MW. Berloque dermatitis mimicking child abuse. Arch Pediatr Adolesc Med. 2002;156(11):1091-3.

22. Snell RS, Turner R. Skin pigmentation in relation to the menstrual cycle. J Invest Dermatol. 1966;47(2):147-55.

23. Jones BC, Hahn AC, Fisher CI, Wincenciak J, Kandrik M, Roberts SC, et al. Facial coloration tracks changes in women's estradiol. Psychoneuroendocrinology. 2015;56:29-34.

24. Alliende ME. Mean versus individual hormonal profiles in the menstrual cycle. Fertil Steril. 2002;78(1):90-5.

25. Gunn DA, Rexbye H, Griffiths CEM, Murray PG, Fereday A, Catt SD, et al. Why some women look young for their age. PLoS One. 2009;4(12):8021.

26. Nkengne A, Bertin C, Stamatas GN, Giron A, Rossi A, Issachar N, et al. Influence of facial skin attributes on the perceived age of Caucasian women. J Eur Acad Dermatology Venereol. 2008;22(8): 982-91.

27. Ebner NC. Age of face matters: Age-group differences in ratings of young and old faces. Behav Res Methods. 2008;40(1):130-6.

28. Fulton JE, Gaminchi F. Sleep lines. Dermatologic Surg. 1999;25(1): 59-62.

29. Voelkle MC, Ebner NC, Lindenberger U, Riediger M. Let me guess how old you are: Effects of age, gender, and facial expression on perceptions of age. Psychol Aging. 2012;27(2):265-77.

30. Hass NC, Weston TD, Lim SL. Be happy not sad for your youth: The effect of emotional expression on age perception. PLoS One. 2016;11(3):0152093.

31. Jones BC, Debruine LM, Little AC, Conway CA, Feinberg DR. Integrating gaze direction and expression in preferences for attractive faces. Psychological Science. 2006;17:588-91.

32. Ganel T, Goodale MA. The effects of smiling on perceived age defy belief. Psychon Bull Rev. 2018;25(2):612-6.

33. Marsh AA, Adams RB, Kleck RE. Why do fear and anger look the way they do? Form and social function in facial expressions. Personal Soc Psychol Bull. 2005;31(1):73-86.

34. Ganel T. Smiling makes you look older. Psychon Bull Rev. 2015;22(6) 1671-7.

35. Weston TD, Hass NC, Lim SL. The Effect of Sad Facial Expressions on Weight Judgment. Front Psychol. 2015;6(MAR):417.

36. Lévêque JL, Goubanova E. Influence of age on the lips and perioral skin. Dermatology. 2004;208(4):307-13.

37. Wong BJF, Karimi K, Devcic Z, McLaren CE, Chen WP. Evolving attractive faces using morphing technology and a genetic algorithm: A new approach to determining ideal facial aesthetics. Laryngoscope. 2008;118(6):962-74.

38. Popenko NA, Tripathi PB, Devcic Z, Karimi K, Osann K, Wong BJF. A quantitative approach to determining the ideal female lip aesthetic and its effect on facial attractiveness. JAMA Facial Plast Surg. 2017;19(4):261-267

39. Gosain AK, Amarante MTJ, Hyde JS, Yousif NJ. A dynamic analysis of changes in the nasolabial fold using magnetic resonance imaging: Implications for facial rejuvenation and facial animation surgery. Plast Reconstr Surg. 1996;98(4):622-36.

40. Vierkotter A, Schikowski T, Ranft U, Sugiri D, Matsui M, Kramer U, et al. Airborne particle exposure and extrinsic skin aging. J Invest Dermatol. 2010;130(12):2719-26.

41. Commo S, Gaillard O, Bernard BA. Human hair greying is linked to a specific depletion of hair follicle melanocytes affecting both the bulb and the outer root sheath. Br J Dermatol. 2004; 150(3):435-43.

42. Kyle DJ. The effects of hair color and cosmeticue on perceptions of a female's ability. Psychol Women Q. 1996;20(3):447-55.

43. Bulpitt CJ, Markowe HLJ, Shipley MJ. Why do some people look older than they should? Postgrad Med J. 2001;77(911):578-81.

44. Fink B, Liebner K, Müller A-K, Hirn T, McKelvey G, Lankhof J. Hair Color and Skin Color Together Influence Perceptions of Age, Health, and Attractiveness in Lightly-Pigmented, Young Women. Int J Cosmet Sci. 2018;40:303-12

45. Cline DJ. Changes in hair color. Dermatol Clin. 1988;6(2):295-303.
46. Sabharwal R, Sargaiyan V, Subudhi S, Gupta S, Mahendra A, Moon $\mathrm{N}$, et al. Association between use of tobacco and age on graying of hair. Niger J Surg. 2014;20(2):83.

47. Nyholt DR, Gillespie NA, Heath AC, Martin NG. Genetic Basis of Male Pattern Baldness. J Invest Dermatol. 2003;121:1561-4.

48. Norwood OT. Male pattern baldness: Classification and incidence. South Med J. 1975;68(11):1359-65

49. Norwood OT. Incidence of female androgenetic alopecia (female pattern alopecia). Dermatol Surg. 2001;27(1):53-4.

50. Varothai S, Bergfeld WF. Androgenetic alopecia: An evidencebased treatment update. American Journal of Clinical Dermatology. 2014;5(3):217-30

51. Hordinsky MK. Overview of Alopecia Areata. J Investig Dermatology Symp Proc. 2013;16(1):13-5.

52. Grover C, Khurana A. Telogen effluvium. Indian J Dermatol Venereol Leprol. 2013; 79(5):591-603

53. Griffiths WAD. Diffuse hair loss and oral contraceptives. $\mathrm{Br} J$ Dermatol. 1973;88(1):31-6.

54. Barcaui CB, Gonçalves Da Silva AM, Sotto MN, Genser B. Stem cell apoptosis in HIV-1 alopecia. J Cutan Pathol. 2006;33(10):667-71.

55. Giacomini F, Starace M, Tosti A. Short anagen syndrome. Pediatr Dermatol. 2011;28(2):133-4.

56. Zeng YP, Wang BX, Fang K. Loose anagen hair syndrome. J Clin Dermatology. 2008;37(5):313-4.

57. Mirmirani P. Hormonal changes in menopause: Do they contribute to a "midlife hair crisis" in women? British Journal of Dermatology. 2011;165:7-11.

58. Batchelor D. Hair and cancer chemotherapy: consequences and nursing care-a literature study. Eur J Cancer Care (Engl). 2001;10(3):147-63

59. Castelo-Branco C, Figueras F, de Osaba MJM, Vanrell JA. Facial wrinkling in postmenopausal women. Effects of smoking status and hormone replacement therapy. Maturitas. 1998;29(1):75-86.

60. Rexbye H, Petersen I, Johansen M, Klitkou L, Jeune B, Christensen $\mathrm{K}$. Influence of environmental factors on facial ageing. Age Ageing. 2006;35(2):110-5.

61. Kennedy C, Bastiaens MT, Bajdik CD, Willemze R, Westendorp RGJ, Bouwes Bavinck JN. Effect of smoking and sun on the aging skin. $J$ Invest Dermatol. 2003;120(4):548-54.

62. Koh JS, Kang H, Choi SW, Kim HO. Cigarette smoking associated with premature facial wrinkling: Image analysis of facial skin replicas. Int J Dermatol. 2002;41(1):21-7.

63. Yaar M, Eller MS, Gilchrest BA. Fifty years of skin aging. J. Investig. Dermatol. Symp. Proc. 2002;7(1);51-8.

64. Darvin ME, Haag S, Meinke M, Zastrow L, Sterry W, Lademann J. Radical production by infrared A irradiation in human tissue. Skin Pharmacol Physiol. 2010; 23(1):40-6

65. Hamer MA, Pardo LM, Jacobs LC, Ikram MA, Laven JS, Kayser M, et al. Lifestyle and Physiological Factors Associated with Facial Wrinkling in Men and Women. J Invest Dermatol. 2017;137(8):1692-9.

66. Mayes AE, Murray PG, Gunn DA, Tomlin CC, Catt SD, Wen YB, et al. Environmental and lifestyle factors associated with perceived facial age in Chinese women. PLoS One. 2010;5(12):15270.

67. Ng TP, Broekman BFP, Niti M, Gwee X, Kua EH. Determinants of successful aging using a multidimensional definition among chinese elderly in singapore. Am J Geriatr Psychiatry. 2009;17(5):407-16

68. Sakata N, Meng J, Jimi S, Takebayashi S. Nonenzymatic glycation and extractability of collagen in human atherosclerotic plaques. Atherosclerosis. 1995;116(1):63-75

69. O'Brien J, Morrissey PA. Nutritional and toxicological aspects of the maillard browning reaction in foods. Crit Rev Food Sci Nutr. 1989;28(3):211-48.

70. Dearlove RP, Greenspan P, Hartle DK, Swanson RB, Hargrove JL. Inhibition of protein glycation by extracts of culinary herbs and spices. J Med Food. 2008;11(2):275-81.

71. Thirunavukkarasu V, Anitha Nandhini AT, Anuradha C V. Fructose diet-induced skin collagen abnormalities are prevented by lipoic acid. Exp Diabesity Res. 2004;5(4):237-44.

72. Tarwadi K V, Agte V V. Effect of micronutrients on methylglyoxalmediated in vitro glycation of albumin. Biol Trace Elem Res. 2011; 143(2):717-25. 
73. Darvin ME, Sterry W, Lademann J, Patzelt A. Alcohol consumption decreases the protection efficiency of the antioxidant network and increases the risk of sunburn in human skin. Skin Pharmacol Physiol. 2012;26(1):45-51.

74. Saladi RN, Nektalova T, Fox JL. Induction of skin carcinogenicity by alcohol and ultraviolet light. Clin Exp Dermatol. 2010;35:7-11

75. Rowe DJ, Guyuron B. Environmental and genetic factors in facial aging in twins. Textbook of Aging Skin. 2010;441-446.

76. Jain N, Chaudhri S. History of cosmetics. Asian J Pharm. 2009;3(3): 164-167.

77. Hawkins S, Subramanyan K. Cleansing, moisturizing, and sunprotection regimens for normal skin, self-perceived sensitive skin, and dermatologist-assessed sensitive skin. Dermatol Ther. 2004;1: 63-8.

78. Krutmann J, Liu W, Li L, Pan X, Crawford M, Sore G, et al. Pollution and skin: From epidemiological and mechanistic studies to clinical implications. Journal of Dermatological Science. 2014;76:163-8.

79. Ayyagari VN, Januszkiewicz A, Nath J. Effects of nitrogen dioxide on the expression of intercellular adhesion molecule-1, neutrophil adhesion, and cytotoxicity: Studies in human bronchial epithelial cells. Inhal Toxicol. 2007;19(2):181-94.

80. Pan TL, Wang PW, Aljuffali IA, Hung YY, Lin CF, Fang JY. Dermal toxicity elicited by phthalates: Evaluation of skin absorption, immunohistology, and functional proteomics. Food Chem Toxicol. 2014;65:105-14.

81. Mancebo SE, Wang SQ. Recognizing the impact of ambient air pollution on skin health. Journal of the European Academy of Dermatology and Venereology. 2015;29:2326-32.

82. Koohgoli R, Hudson L, Naidoo K, Wilkinson S, Chavan B, Birch-Machin MA. Bad air gets under your skin. Exp Dermatol. 2017;26(5):384-7.

83. Zhou L. AHR Function in Lymphocytes: Emerging Concepts. Trends Immunol. 2016;37(1):17-31.

84. Dunn J, Koo J. Psychological Stress and skin aging: a review of possible mechanisms and potential therapies. Dermatol Online J. 2013;19(6):1-19.

85. Chung HY, Sung B, Jung KJ, Zou Y, Yu BP. The Molecular Inflammatory Process in Aging. Antioxid Redox Signal. 2006; 8(3-4): 572-81.

86. Lu T, Pan Y, Kao SY, Li C, Kohane I, Chan J, et al. Gene regulation and DNA damage in the ageing human brain. Nature. 2004; 429(6994): 883-91.
87. Palmer DM, Kitchin JS. Oxidative damage, skin aging, antioxidants and a novel antioxidant rating system. JDD. 2010;9:11-5.

88. Draelos ZD. Aging skin: The role of diet: Facts and controversies. Clin Dermatol. 2013;31:701-6.

89. Daniel S, Reto M, Fred Z, Cosmetics MAG. Collagen glycation and skin aging. Switzerland: Cosmet Toilet Manufactrue Worldw. 2001:1-7

90. Makrantonaki E, Zouboulis CC. William J. Cunliffe Scientific Awards. Characteristics and pathomechanisms of endogenously aged skin. Dermatology. 2007;214(4):352-60.

91. Beisswenger PJ, Howell S, Mackenzie T, Corstjens H, Muizzuddin N, Matsui MS. Two fluorescent wavelengths, $440(\mathrm{ex}) / 520(\mathrm{em}) \mathrm{nm}$ and $370(\mathrm{ex}) / 440(\mathrm{em}) \mathrm{nm}$, reflect advanced glycation and oxidation end products in human skin without diabetes. Diabetes Technol Ther. 2012; 4(3):285-92

92. Gkogkolou P, Bohm M, Böhm M. Advanced glycation end products: key players in skin ageing? Dermatoendocrinol. 2012;4(3):259-70

93. Buonocore G, Perrone S, Tataranno ML. Oxygen toxicity: Chemistry and biology of reactive oxygen species. Semin Fetal Neonatal Med. 2010;15(4):186-90.

94. Kohen R, Nyska A. Oxidation of biological systems: Oxidative stress phenomena, antioxidants, redox reactions, and methods for their quantification. Toxicologic Pathology. 2002;30:620-50.

95. Bar-Or D, Bar-Or R, Rael LT, Brody EN. Oxidative stress in severe acute illness. Redox Biology. 2015;4:340-5.

96. Lephart ED. Skin aging and oxidative stress: Equol's anti-aging effects via biochemical and molecular mechanisms. Ageing Research Reviews. 2016;31:36-54.

97. Etcoff NL, Stock S, Haley LE, Vickery SA, House DM. Cosmetics as a feature of the extended human phenotype: Modulation of the perception of biologically important facial signals. PLoS One. 2011; 6(10):25656.

98. Huguet P, Croizet JC, Richetin J. Is "what has been cared for" necessarily good? Further evidence for the negative impact of cosmetics use on impression formation. J Appl Soc Psychol. 2004; $34(8) ; 1752-71$.

99. Webster, M, Driskell, JE. Beauty as Status. Am J Sociol. 1983;89: $140-65$

100. Nash R, Fieldman G, Hussey T, Lévêque JL, Pineau P. Cosmetics: They influence more than Caucasian female facial attractiveness. Br J Soc Psychol. 2006;36:493-504. 